\title{
Effect of disodium octaborate tetrahydrate on the mechanical properties of Dendrocalamus asper bamboo treated by vacuum/pressure method
}

\author{
Christian Gauss", Marzieh Kadivar and Holmer Savastano Jr.
}

\begin{abstract}
The chemical treatments applied to some lignocellulosic resources commonly used as building materials can influence their mechanical performance during service, and hence, this effect should be studied for structural safety reasons. In this piece of work, prismatic samples of Dendrocalamus asper bamboo were treated in a vacuum/pressure process with disodium octaborate tetrahydrate (DOT) solutions and the corresponding mechanical performance was compared with non-treated and water-treated samples. Full penetration of boron was achieved, with DOT retentions of $14.79 \mathrm{~kg} \mathrm{~m}^{-3}$ and $21.79 \mathrm{~kg} \mathrm{~m}^{-3}$ for $5 \%$ and $8 \%$ (wt/wt\%) solutions, respectively. Dynamic modulus of elasticity (MOE), static MOE, and compressive modulus of elasticity of the material, with values between 23.3-24.0, 15.9-16.2, and 26.2-27.2 GPa, respectively, were statistically equivalent for all the analyzed treatment conditions. However, a significant influence of the treatment could be observed on the specific compressive strength of bamboo, showing an increase of $35.3 \%$ for the $5 \%$ solution and $30.6 \%$ for the $8 \%$ solution. Although without statistical difference among the treatments, similar behavior was observed on the specific modulus of rupture (MOR) under flexural loading, with an increase of up to $10.1 \%$ in relation to the reference for the treated samples. The results achieved in the present study from nondestructive excitation pulse, three-point bending, and axial compression tests demonstrated that mechanical behavior of bamboo was preserved or even enhanced by the proposed treatments based on disodium octaborate tetrahydrate.
\end{abstract}

Keywords: Bamboo, Bending, Compression, Dendrocalamus asper, Disodium octaborate tetrahydrate, Treatment

\section{Introduction}

Developing and using low embodied carbon building materials and services, at the life cycle perspective, is identified as one of the main pivotal opportunities to reduce the carbon emissions of the construction sector [1]. The construction industry requires heavy investment, produces intensive pollutions [2], and accounts for around $36 \%$ of worldwide $\mathrm{CO}_{2}$ emissions [3]. Biobased construction materials have the advantage of not only being renewable but also having a significant

${ }^{*}$ Correspondence: gausschr@usp.br

Biosystems Engineering Department, University of São Paulo, Pirassununga, SP 13635-900, Brazil contribution to carbon sequestration during their growth $[4,5]$, as well as carbon storage during their use phase [6].

Life cycle assessment studies of bamboo-based construction materials clearly showed the potential of bamboo for use in the construction sector [7-10]. In these studies, transportation is an important issue to a product such as bamboo culm which has a high volume per mass. There is a large environmental impact of transferring such raw materials from its origin to site of construction, and this, therefore, makes the use of local materials (local bamboo species) indisputable in the industrial and construction sectors.

The excellent physical and mechanical properties of bamboo have led to its empirical use in construction and have attracted the attention of several researchers to start 
the process of rediscovering bamboo recently [11]. Even for modern buildings, bamboo has been widely employed to fabricate mechanical elements and structures [12, 13] and it is frequently referred as a high-strength alternative material to timber and occasionally as a 'strong-as-steel' reinforcement for concrete [14].

However, bamboo properties are directly related to the species, age, moisture content, soil, harvest season, and culm geometry among other factors [15]. The mechanical strength of $D$. asper, a species which has been used in this research, in compression, tension, and bending is reported to be 53 to $95 \mathrm{MPa}, 73$ to $326 \mathrm{MPa}$, and 95 to $258 \mathrm{MPa}$, respectively, depending on the presence or absence of the node and the position in relation to the culm height [16-20]. These mechanical properties are medium to higher than those of other species of Dendrocalamus genera, Guadua and Bambusa [21, 22].

Along with mechanical strength adequate to the requirements of different applications, a building material should have an acceptable life span. The durability of untreated bamboo varies based on the species, age, and conservation actions taken, and it is strongly related to the bamboo chemical composition $[16,23$, 24]. In an open environment, and in the contact with soil, bamboo is estimated to last 1 to 3 years, 4 to 6 years if undercover, and free from soil contact [25, 26]. Only under very favorable use conditions such as internal framing is untreated bamboo estimated to last around 15 years [11] which is not sufficient as a construction material.

The powderpost beetle (Dinoderus minutus) which is the main destructive agent of bamboo [27], and other xylophagous organisms, such as decay fungi and termites, can seriously affect its structural integrity and consequently compromise the service life of the resulting structures or constructive systems [26, 28]. Additionally, flammability, the volume variation due to water absorption, and the susceptibility to chemical degradation are other problems that hinder their use in some applications [29, 30]. Therefore, an adequate preservative treatment of bamboo is necessary so that it can be safely used as a structural element. There are several treating methods to improve the durability and preserve bamboo materials, but some methods which use thermal and natural products like vegetable oils (palm, sunflower, or soybean) have been proved to decrease the mechanical properties of bamboo [31-33]. Wahab et al. [34] studied tropical bamboo treated in palm oil at 140, 180 , and $220{ }^{\circ} \mathrm{C}$ during 30,60 , and $90 \mathrm{~min}$. The results showed that the treatment decreased the mechanical properties (bending, compressive, and shear strengths). When the treatment duration increases, the mechanical strengths could decrease by $15-58 \%$ from the initial strength, depending on each treatment procedure and each mechanical property [35]. On the other hand, some treatments lead to color changes [36,37], which is an undesirable effect [35].

Since ancient times, chemical methods have been used for wood and bamboo preservation and while non-chemical methods have also been used, the chemical methods are considered as more appropriate for bamboo preservation in large-scale building projects [11]. There are a lot of chemical materials that have been used to preserve wood and bamboo against water, insect, and fungal attack and as a fire retardant. However, the use of some chemical preservatives is ambivalent. For example, conventional wood treatment solutions used in Brazil have good performance but are normally based on heavy metals and other toxic elements, such as chromated copper arsenate (CCA) and pentachlorophenol, which have an impact on animals and plants.

Among the various substances and their mixtures that have been suggested, investigated, and commercialized, the use of low-cost soluble salts, such as boronbased salts specifically disodium octaborate tetrahydrate (DOT), boric acid, and borax, is interesting alternatives for the treatment of bamboo and wood [24, 28, 38, 39]. Boron compounds are some of the most effective and versatile preservatives solutions used nowadays since they combine the broad-spectrum efficacy, low mammalian toxicity, odorless, colorless, and fire-retardant properties [40-43]. The preservation method with boron compounds can be even a way to improve the quality of bamboo, increasing the tensile strength in comparison with bamboo without preservatives $[44,45]$.

Bamboo requires essential preservation treatment before its utilization as a structural material to ensure the durability of a building. Although chemical treatment is considered a commonly used treatment procedure in the construction industry, it might damage the material mechanically. Therefore, the influence of chemical treatments in the mechanical properties of those building materials must be known. It is worth mentioning that most part of the structural projects using bamboo in Latin America and Asia use boron compounds (boric acid, borax or DOT) as the main preservative and therefore studies of treatability, mechanical performance, and durability are necessary. In spite of the high use of DOT, which is an active component in Bora-Care ${ }^{\circledR}$ and is an available popular commercial preservative, to the best of our knowledge, there has been no prior comprehensive study on the effect of this type of treatment on bamboo with regard to the mechanical performance.

The objectives of this work were to determine the retention of DOT for treated bamboo and evaluate the effects of DOT treatment on mechanical properties assessed by 
nondestructive test by excitation pulse, three-point static bending, and axial compression tests.

\section{Materials and methods}

\section{Materials and sample preparation}

The $D$. asper bamboo species has been used for this study due to its availability and easy access in several tropical regions. Bamboo culms were harvested at the experimental field in the University of São Paulo Campus at Pirassununga, Brazil $\left(21^{\circ} 58^{\prime} 53.5^{\prime \prime} \mathrm{S} 47^{\circ} 26^{\prime} 03.3^{\prime \prime} \mathrm{W}\right)$. The referred collection area is located at an altitude of $630 \mathrm{~m}$ above the sea level, with an annual average rainfall of $1363 \mathrm{~mm}$ and tropical climate with well-defined seasons (rainy summer and dry winter).

Mature culms (more than 3 years old) were collected and conditioned in a protected environment for drying until reaching constant moisture content. Tangentially oriented strips, approximately $250 \mathrm{~mm}$ long and $20 \mathrm{~mm}$ wide, were then cut from the inner region between nodes, also called internodes. Since the samples have been taken from the same or adjacent internodes, a possible influence of the variation of the mechanical properties along the culm in the effect of each treatment was minimized. Then, the samples were sanded to obtain dimensional uniformity in width and thickness.

The physical properties of the samples, moisture content $(\mathrm{MC})$ and apparent density $(\rho)$, before treating with DOT are listed in Table 1. Internodes (Int) of two different culms have been used for this study. Int A in the table stands for the samples taken from the middle part of a bamboo culm with the external diameter of approximately $11 \mathrm{~cm}$ and Int $\mathrm{B}$, taken from the bottom part of a bamboo culm with approximately $16 \mathrm{~cm}$ external diameter.

\section{Treatment procedures}

A combination of boric acid and disodium borate decahydrate was used in the ratio of $1: 1.54$ by mass for the formation of DOT, $\left(\mathrm{Na}_{2} \mathrm{~B}_{8} \mathrm{O}_{13} \cdot 4 \mathrm{H}_{2} \mathrm{O}\right)$ according to the stoichiometric reaction:

$$
\begin{aligned}
& \mathrm{Na}_{2} \mathrm{~B}_{4} \mathrm{O}_{7} \cdot 10 \mathrm{H}_{2} \mathrm{O}+4 \mathrm{H}_{3} \mathrm{BO}_{3} \\
& \quad \rightarrow \mathrm{Na}_{2} \mathrm{~B}_{8} \mathrm{O}_{13} \cdot 4 \mathrm{H}_{2} \mathrm{O}+12 \mathrm{H}_{2} \mathrm{O}
\end{aligned}
$$

Table 1 Apparent density ( $\rho)$ and moisture content (MC) of the bamboo samples used for treatment (COV in parentheses)

\begin{tabular}{lll}
\hline & $\boldsymbol{\rho}\left(\mathbf{g ~ c m}^{\mathbf{3}}\right)$ & MC (\%) \\
\hline $\operatorname{lnt} A$ & $0.69(0.043)$ & $8.3(0.012)$ \\
$\operatorname{lnt~B}$ & $0.77(0.026)$ & $8.7(0.023)$ \\
\hline
\end{tabular}

Boric acid and disodium borate decahydrate of analytical grade were used. Then, aqueous solutions of the preservatives with concentrations of $5 \%$ and $8 \%(\mathrm{wt} / \mathrm{wt} \%)$ were prepared using distilled water for the impregnation procedure. These concentrations were selected based on recommendations of bamboo treatment manuals of the International Network of Bamboo and Rattan (INBAR) (with concentrations between 5 and 10\%), Indian Standard of preservation of bamboo for structural purposes (concentration of 4 and 5\%), and other related papers [24, 46, 47]. Additionally, those are concentrations normally used in bamboo treatment plants around Colombia and Brazil.

The obtained solutions were applied through a vacuum/pressure steel chamber with a diameter of $150 \mathrm{~mm}$ and $270 \mathrm{~mm}$ height. This method was adopted to guarantee the penetration of the boron compounds in the samples. Prior to treatment, the samples were oven-dried at $60 \pm 5{ }^{\circ} \mathrm{C}$ until constant weight.

First, the specimens were placed in the empty chamber under an initial vacuum $(-650 \mathrm{mmHg})$ for $15 \mathrm{~min}$ with the intention of withdrawing air from the chamber and from the bamboo structure. Thereafter, the solution was injected into the chamber (about $8 \mathrm{~L}$ was required for total immersion of the samples) and the same vacuum was maintained for an additional $1 \mathrm{~h}$. Then, a pressure of approximately $3103 \mathrm{mmHg}$ (60 psi) was applied into the chamber and held constant for $1 \mathrm{~h}$. After this step, the solution was drained and the samples were taken out from the chamber and left in room temperature for $48 \mathrm{~h}$ and then dried at $(100 \pm 2){ }^{\circ} \mathrm{C}$ for $48 \mathrm{~h}$. After the drying process, the samples were conditioned in a climatic chamber at $25^{\circ} \mathrm{C}$ and $70 \% \mathrm{RH}$ prior to mechanical testing.

\section{Retention and boron penetration}

Retention is usually expressed as weight of chemical per unit volume of wood (pounds per cubic foot or kilograms per cubic meter) or on weight of chemical to weight of wood basis (wt/wt\%). The weights of the specimens were measured before and shortly after the treatment to determine the absorption of the treatment solution, and then, the theoretical retention was calculated using Eq. 1, as per AWPA E10:2016 Standard [48].

$$
R\left(\mathrm{~kg} \mathrm{~m}^{-3}\right)=\frac{A b \times C_{\mathrm{w}}}{V} \times 10
$$

where $R$ is the DOT retention $\left(\mathrm{kg} \mathrm{m}^{-3}\right) ; A b$ mass of absorbed solution after treatment $(\mathrm{g}) ; C_{\mathrm{w}}$ concentration of the preservative solution (wt/wt) (\%); and $V$ sample volume $\left(\mathrm{cm}^{3}\right)$. 
The penetration analysis was also performed on samples treated with the boron compounds according to Brazilian Standard ABNT NBR 6232:2013 (Penetration and retention of preservatives in pressure treated wood) and Indian Standard IS 1902:2006 (Preservation of bamboo and cane for non-structural purposes) to observe the presence of boron $[46,49]$. A cross-sectional area of $(10 \times 20) \mathrm{mm}^{2}$ from samples extracted from the central region of the treated prismatic specimens was reacted with two different etching solutions. Solution 1 is composed of curcumin (earth turmeric) and ethyl alcohol (10\% wt/vol alcohol) and solution 2 composed of a saturated salicylic acid alcoholic solution $(13 \mathrm{~g}$ to $100 \mathrm{~mL}$ solution) and $20 \mathrm{~mL}$ of concentrated hydrochloric acid. First, solution 1 is applied, and when dried, solution 2 is used. The observation of red color indicates the presence of boron. Except for turmeric, all reagents used are analytical grade.

\section{Mechanical tests}

Samples originated from Int A and Int B were used for the mechanical characterization, with a total of eight specimens per treatment condition: reference, water treated, DOT 5\% solution, DOT 8\% solution). Each sample was subjected to the three tests performed in this work (excitation pulse, three-point bending, and axial compression tests).

\section{Excitation pulse nondestructive test}

The dynamic elastic modulus was determined for each sample which was subsequently tested via static bending and in compression. The tests were performed in an excitation pulse testing machine Sonelastic ${ }^{\circledR}$, as per recommendations of the ASTM E1876-15 Standard [50]. The dynamic modulus of elasticity was determined in the longitudinal and flexural mode. Samples with nominal dimensions of $250 \mathrm{~mm} \times 20 \mathrm{~mm} \times$ thickness were used with a gap between the inferior supports of $0.552 \times \mathrm{L}$.

\section{Three-point bending test}

After the determination of the dynamic elastic modulus by the impulse excitation technique, the same samples were subjected to a static three-point bending test using a universal testing machine EMIC model DL30000. The supported distance for each specimen was $L=160 \mathrm{~mm}$, and single point load $F$ was applied at $L / 2$. These dimensions are established in order to maintain a minimum length-to-depth ratio of 15 (according to the ASTM D1037-12 Standard) [51]. The specimens were loaded continuously until failure at a loading rate of $5 \mathrm{~mm} \mathrm{~min}{ }^{-1}$, and a deflectometer was used to record the deflection in the center of the specimen. The modulus of rupture (MOR) and the modulus of elasticity (MOE) were then calculated according to Eqs. 2 and 3.

$$
\begin{aligned}
& \operatorname{MOR}(\mathrm{MPa})=\frac{3 \times F_{\mathrm{r}} \times D}{2 \times w \times\left(t^{2}\right)} \\
& \operatorname{MOE}(\mathrm{MPa})=\frac{F_{\mathrm{LP}} \times\left(D^{3}\right)}{4 \times d \times w \times\left(t^{3}\right)}
\end{aligned}
$$

where $F_{\mathrm{r}}$ is the load at failure $(\mathrm{N}) ; D$ distance between the supports $(\mathrm{mm}) ; w$ width of the sample $(\mathrm{mm}) ; t$ thickness of the sample $(\mathrm{mm}) ; F_{\mathrm{LP}}$ maximum load in the elastic region $(\mathrm{N}) ; d$ deflection related to $F_{\mathrm{LP}}(\mathrm{mm})$.

\section{Axial compression tests}

Compression tests parallel to fibers were conducted in a servohydraulic test system, MTS Landmark, with a 15 $\mathrm{kN}$ load cell. Before the official axial compression tests, several tests were carried out to evaluate the applied methodology. First, the deformation difference between the inner and outer faces of the bamboo was evaluated. In samples extracted from the same specimens that were used in the bending tests, an extensometer was placed on the outer and the inner layers. It was found that due to the dimensions of the specimen, there was no significant difference between the different positions.

After the static bending test, two samples of approximate dimensions of $40 \mathrm{~mm} \times$ width $\times$ thickness (width $=$ thickness) per test piece were cut. The test was performed at a rate of $10 \mathrm{MPa} \mathrm{min}{ }^{-1}$, according to the recommendations of the Brazilian ABNT NBR 7190:1997 Standard (Wood Structures Project) and within the recommended testing time of ASTM D4761-13 [52, 53]. First, a test specimen was used to determine the compressive strength, without the use of extensometer, calculated using the maximum load at failure. Then, a second specimen (of the same sample used in bending) was used to determine the compressive modulus of elasticity. In this step, two loading cycles were performed between 20 and $50 \%$ of the compressive strength (determined previously), as shown in Fig. 1. The elastic modulus was then calculated through linearization of the second loading step. After the double loading, the extensometer was withdrawn, and the test continued until failure of the specimen.

\section{Statistical analysis}

The averages of the results from each test are presented with the corresponding coefficient of variation (COV presented in parentheses). The differences between the treatment conditions on the mechanical properties were checked by a Tukey's test and analysis of variance (ANOVA) $(p<0.05)$ in case of a significant difference. For 

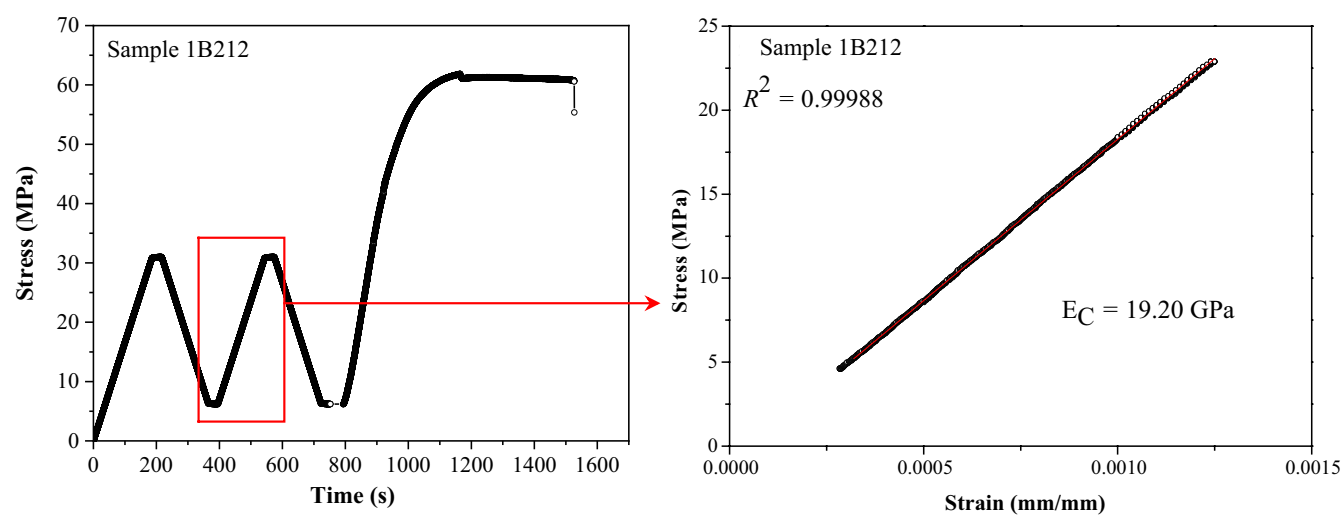

Fig. 1 Loading cycles used for determination of modulus of elasticity in the axial compression tests

Table 2 Absorption of solution after the treatment process in the vacuum/pressure vessel

\begin{tabular}{llll}
\hline \multicolumn{4}{l}{ Absorption after impregnation, weight increase (\%) } \\
\hline Treatment & Int A & Int B & Overall \\
\hline Water & $67.6(0.20)$ & $57.9(0.17)$ & $61.6(0.19)$ \\
$5 \%$ DOT & $73.1(0.031)$ & $61.3(0.059)$ & $65.7(0.10)$ \\
$8 \%$ DOT & $65.7(0.11)$ & $55.4(0.052)$ & $58.8(0.11)$ \\
\hline
\end{tabular}

the statistical analysis, normalized mechanical properties in relation to density (also called specific property) were used in order to better observe the effect of each treatment. All analyses were performed by the software MINITAB ${ }^{\circledR}$ Release 14 Statistical Software.

\section{Results and discussion}

\section{Retention and boron penetration}

Table 2 shows the analyzed solution absorption values of each condition. Apparently, despite increasing the viscosity of the solution, the concentration of DOT did not significantly affect the absorption of the solution compared to water. However, it is noticed that the absorption is correlated with the density, as shown in Fig. 2. This relationship is related to the number of pores since the solution uptake is strongly dependent on wood/bamboo permeability [54].

In general, the treatment involves placing an adequate amount of chemical to a depth that will achieve the desired degree of protection. Thus, most treatment standards address penetration or the depth to which the chemical penetrates and the retention, or the amount of chemicals deposited in a specific area of the wood [55]. The retention values calculated according to Eq. 1 are presented in Table 3. It is worth mentioning that these theoretical values have been calculated considering the

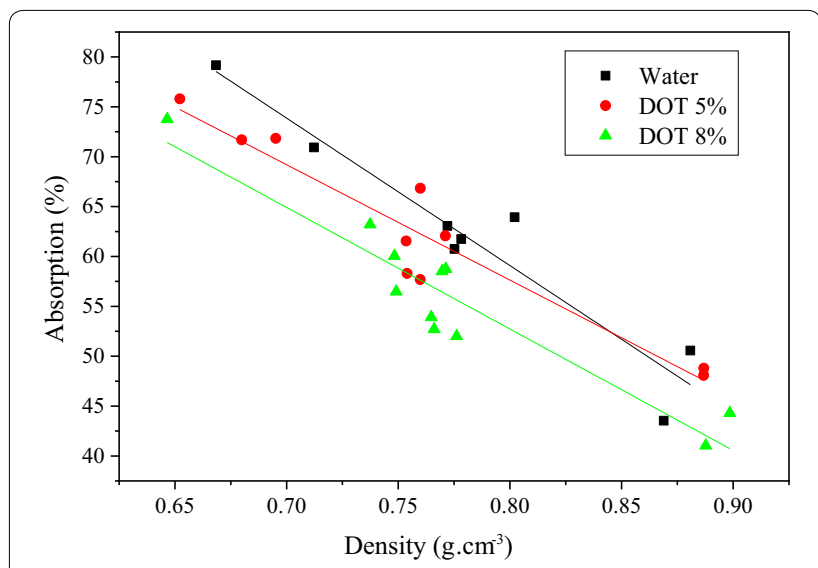

Fig. 2 Relationship between solution absorption and the apparent density of bamboo samples

absorption of the treatment solution. The retention is presented as the equivalent of dried DOT per unit volume of bamboo. According to the stoichiometric reaction shown previously, for solutions based on boric acid and borax in the proportion of 1:1.54 (wt:wt), the resulting mass of DOT is $65.6 \%$ from the total mass of boric acid and borax. For the 5\% solution, for example, the mass of absorbed solution is multiplied by 0.328 to have the corresponding amount of formed DOT. The results given in Table 3 can also be represented as the retention of $\mathrm{B}_{2} \mathrm{O}_{3}$ per unit volume of bamboo. In the case of DOT, $\mathrm{B}_{2} \mathrm{O}_{3}$ represents $79.91 \%$ of its molecular weight, resulting in retention of $11.82 \mathrm{~kg} \mathrm{~m}^{-3}$ and $17.41 \mathrm{~kg} \mathrm{~m}^{-3}$ for the $5 \%$ and $8 \%$ solutions, respectively. These both results satisfy the desired $\mathrm{B}_{2} \mathrm{O}_{3}$ retention as recommended by American Wood Preservers' Association $\left(2.7 \mathrm{~kg} \mathrm{~m}^{-3}\right)$ [38] and the Indian Standard IS401:2001 $\left(5 \mathrm{~kg} \mathrm{~m}^{-3}\right)$ for indoor use application of wood [56]. Although acceptable retention levels were obtained, compared to sapwood, the 
Table 3 Retention values of DOT calculated according to Eq. 1

\begin{tabular}{llll}
\hline \multicolumn{4}{l}{ Retention of DOT $\left(\mathbf{k g ~ m}^{\mathbf{3}}\right)$} \\
\hline Treatment & Int A & Int B & Overall \\
\hline 5\% DOT & $15.28(0.012)$ & $14.35(0.061)$ & $14.79(0.056)$ \\
$8 \%$ DOT & $22.93(0.030)$ & $20.65(0.047)$ & $21.79(0.063)$ \\
\hline
\end{tabular}

retention levels of bamboo are smaller mainly because of its anatomical structure. The bamboo used in this work has higher density than Scots pine $\left(0.4-0.5 \mathrm{~g} \mathrm{~cm}^{-3}\right)$, for example, which limits the maximum amount of solution that can be absorbed by the material. In sapwood treatment, more than $100 \%$ of its weight can be absorbed. In bamboo, the outer layer part of the culm wall is protected by an epidermis as a waterproof seal. Additionally, there are no radial penetration pathways in bamboo, like the rays in wood. Especially in dry bamboo, the main path for penetration is the metaxylem vessels of the vascular bundles and the access to the parenchyma is difficult [24, $47,57]$.

In Fig. 3, photographs obtained through a stereoscope show the total penetration of boron over the thickness of the treated samples (Fig. 3b). In Fig. 3a, an image of a sample without treatment subjected to the test is presented for comparison. Both samples treated with 5\% and $8 \%$ DOT solutions showed similar staining and total penetration.

\section{Mechanical characterization \\ Dynamic modulus of elasticity}

Nondestructive testing (NDT) was used to evaluate the dynamic modulus of elasticity of treated and untreated bamboo samples. Since bamboo is a natural composite composed of aligned fiber bundles in the growth direction in a parenchyma matrix, it is expected an anisotropic behavior. Therefore, the measurements were taken in flexural and longitudinal mode.

Figure 4 shows the relationship between the dynamic MOE and density of each sample. There is an almost linear correlation between the dynamic MOE and density of bamboo. This observation is correlated with the fact that higher density in bamboo means higher volume fraction of fibers within its structure. Dixon et al. [58] found the same relationship between the MOE (obtained by static flexure tests) and the density of the bamboo species Moso, Tre Gai, and Guadua, with MOE varying between 10 and $40 \mathrm{GPa}$.

A summary of the achieved results for each treatment condition is given in Table 4. Since there is a correlation of the dynamic MOE with density (Fig. 4) and in order to better compare the effect of each treatment condition, the specific MOE was calculated for each specimen and an average for the eight samples was obtained. It can be observed that even with high retention, there was no significant change in the dynamic MOE among the investigated conditions and the preservatives have no negative

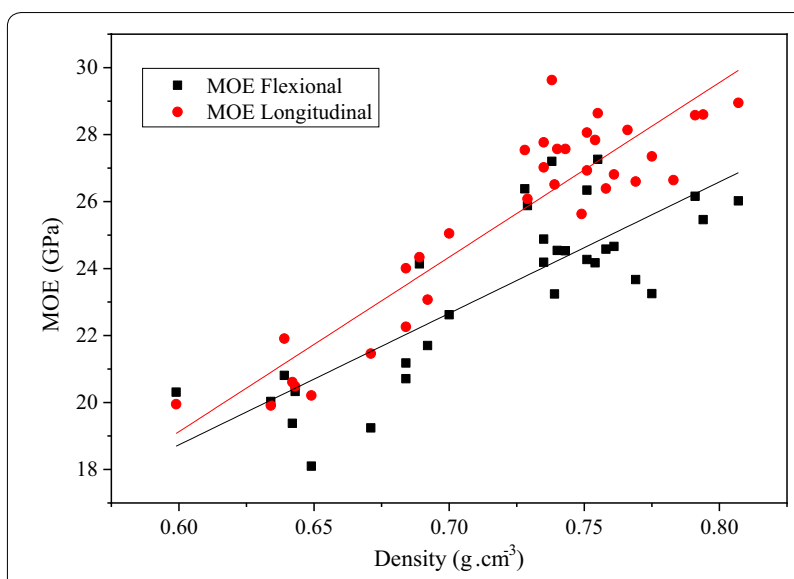

Fig. 4 Correlation between dynamic MOE (flexural and longitudinal modes) and apparent density

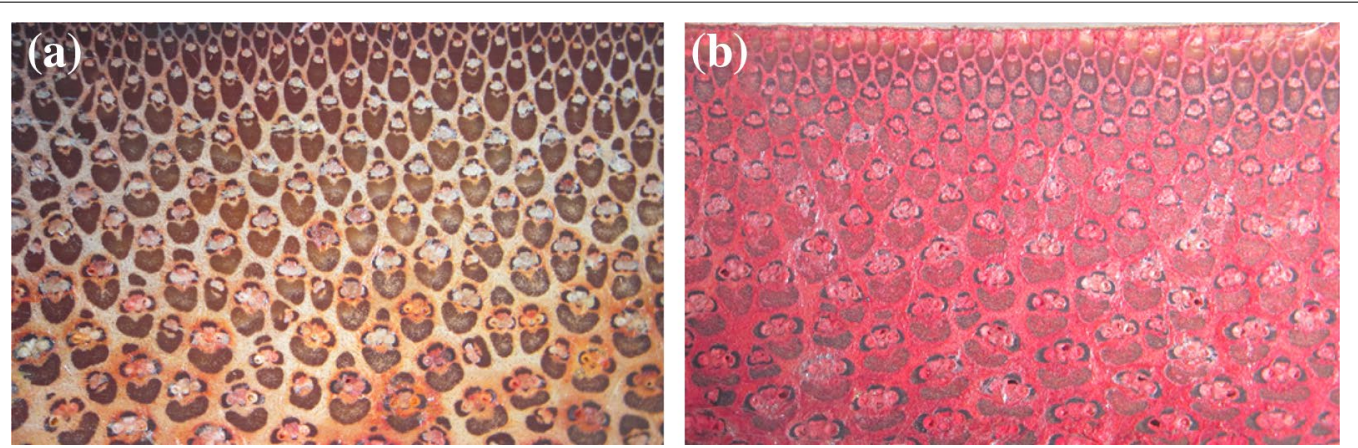

Fig. 3 Analysis of penetration with solution of curcumin and salicylic acid. $\mathbf{a}$ The solution was used in an untreated sample and $\mathbf{b}$ the treated sample 
Table 4 Summary of NDT excitation pulse measurements for determination of the dynamic MOE

\begin{tabular}{|c|c|c|c|}
\hline Treatment conditions & MC (\%) & $\begin{array}{l}\text { Flexural MOE } \\
(\mathrm{GPa})\end{array}$ & $\begin{array}{l}\text { Longitudinal MOE } \\
\text { (GPa) }\end{array}$ \\
\hline \multicolumn{4}{|l|}{ Reference } \\
\hline Int A & 10.72 & $20.91(0.033)$ & $21.94(0.060)$ \\
\hline Int B & & $24.57(0.091)$ & $27.99(0.031)$ \\
\hline Overall Avr & & $23.35(0.067)$ & $25.97(0.12)$ \\
\hline Specific $^{1}$ & & $31.26(0.044)^{\mathrm{a}}$ & $34.67(0.051)^{\mathrm{a}}$ \\
\hline \multicolumn{4}{|l|}{ Water } \\
\hline $\operatorname{lnt} A$ & 9.37 & $21.44(0.11)$ & $22.29(0.085)$ \\
\hline Int B & & $24.34(0.19)$ & $26.36(0.044)$ \\
\hline Overall Avr & & $23.25(0.17)$ & $24.83(0.10)$ \\
\hline Specific $^{1}$ & & $32.53(0.14)^{\mathrm{a}}$ & $34.73(0.039)^{\mathrm{a}}$ \\
\hline \multicolumn{4}{|l|}{$5 \%$ DOT } \\
\hline $\operatorname{lnt} A$ & 10.24 & $19.22(0.057)$ & $20.54(0.039)$ \\
\hline Int B & & $25.79(0.067)$ & $28.02(0.042)$ \\
\hline Overall Avr & & $23.26(0.15)$ & $24.90(0.16)$ \\
\hline Specific $^{1}$ & & $33.34(0.10)^{\mathrm{a}}$ & $35.61(0.091)^{\mathrm{a}}$ \\
\hline \multicolumn{4}{|l|}{ 8\% DOT } \\
\hline Int A & 10.23 & $22.36(0.14)$ & $23.33(0.13)$ \\
\hline Int B & & $24.76(0.032)$ & $27.33(0.017)$ \\
\hline Overall Avr & & $23.96(0.086)$ & $26.00(0.099)$ \\
\hline Specific $^{1}$ & & $32.99(0.044)^{\mathrm{a}}$ & $35.76(0.051)^{\mathrm{a}}$ \\
\hline
\end{tabular}

${ }^{1} \mathrm{MOE}(\mathrm{GPa}) / \rho\left(\mathrm{g} \mathrm{cm}^{-3}\right)$. Specific averages with the same letter (a-d) are statically equivalent. Three replicates were tested for Int $A$ and five for Int $B$, with a total of eight replicates per treatment condition

effect on bamboo samples in terms of MOE in both flexural and longitudinal directions. Although a slight increase was observed, $6.65 \%$ and $5.53 \%$ on the flexural $\mathrm{MOE}$ and $2.7 \%$ and $3.14 \%$ on the longitudinal MOE for the $5 \%$ and $8 \%$ DOT-treated samples, respectively, these results are statistically equivalent to the reference samples.

\section{Three-point bending}

According to the previous discussion, there is a correlation between the dynamic MOE and apparent density. Similar behavior could be observed with the modulus of rupture obtained by static bending, corroborating with the observations of other authors [58]. Therefore, specific values of MOR and MOE were also calculated for all the samples.

The stress-strain curves of several samples from all the conditions (reference, water, $5 \%$ and $8 \%$ DOT) are shown in Fig. 5, and the results of MOR and MOE are given in Table 5. It is possible to observe that all the curves, independently of the applied treatment, showed similar behavior upon straining. The obtained average values of MOR, between 150.4 and 167.2 MPa, are similar to those observed by other authors in the same bamboo species, in which values between 140 and $258 \mathrm{MPa}$ were reported using comparable testing procedure $[17,20]$.

According to the results given in Table 5, although a slight increase in the average specific MOR of the samples treated with DOT was observed $(8.5 \%$ and $10.1 \%$ for the $5 \%$ and $8 \%$ treatments, respectively), this difference is not statistically relevant using the ANOVA. The same behavior was noticed for the results of MOE, in which case there was no considerable effect of the treatments with DOT. Comparing the results of MOE obtained by static bending and by excitation pulse test, it was observed that the dynamic data were approximately $55 \%$ higher than the static MOE. In fact, this difference is normally found in NDT tests for the determination of dynamic MOE, with a difference between 40 and $50 \%[59,60]$.

It is worth mentioning that since the same specimens were used for NDT and static bending tests, a correlation between the obtained data through both techniques can be made. Figure 6 shows the relationship between the longitudinal dynamic MOE and static MOR. Interestingly, although they describe different mechanical properties, there is an almost linear correlation between them $\left(R^{2}=0.8629\right)$. This observation can be very useful for quality control of bamboo products since a nondestructive test could be used to estimate other properties normally obtained only by destructive and time-consuming tests.

\section{Compression parallel to the fibers}

The compressive modulus of elasticity $\left(E_{\mathrm{C}}\right)$ was determined by following the stress-time pattern shown in Fig. 1. Very good linearization $\left(R^{2}=0.9998\right)$ of the stressstrain plot was obtained using the second loading step, assuring good quality of the extracted $E_{\mathrm{c}}$.

A summary of the compressive strength $\left(C_{\mathrm{S}}\right)$ and $E_{\mathrm{C}}$ results obtained for the DOT-treated, water-treated, and reference samples is presented in Table 6. From the results, the influence of preservative treatment also did not have any significant effect on the compressive modulus of elasticity, corroborating with the elastic properties obtained by static bending and excitation pulse tests. However, on compressive strength, a positive and statistically different effect of the treatment can be observed. The samples treated with $5 \%$ and $8 \%$ DOT solutions presented a specific $C_{\mathrm{S}}$ increase of $35.3 \%$ and $30.6 \%$, respectively, in comparison with the reference samples. The water-treated samples also had a slight increase in the compression strength (17.1\%). Similar behavior was observed in the MOR obtained by static bending, although statistical analysis showed no valid difference.

According to the results of the mechanical tests, the solutions used for treatment did not cause any 

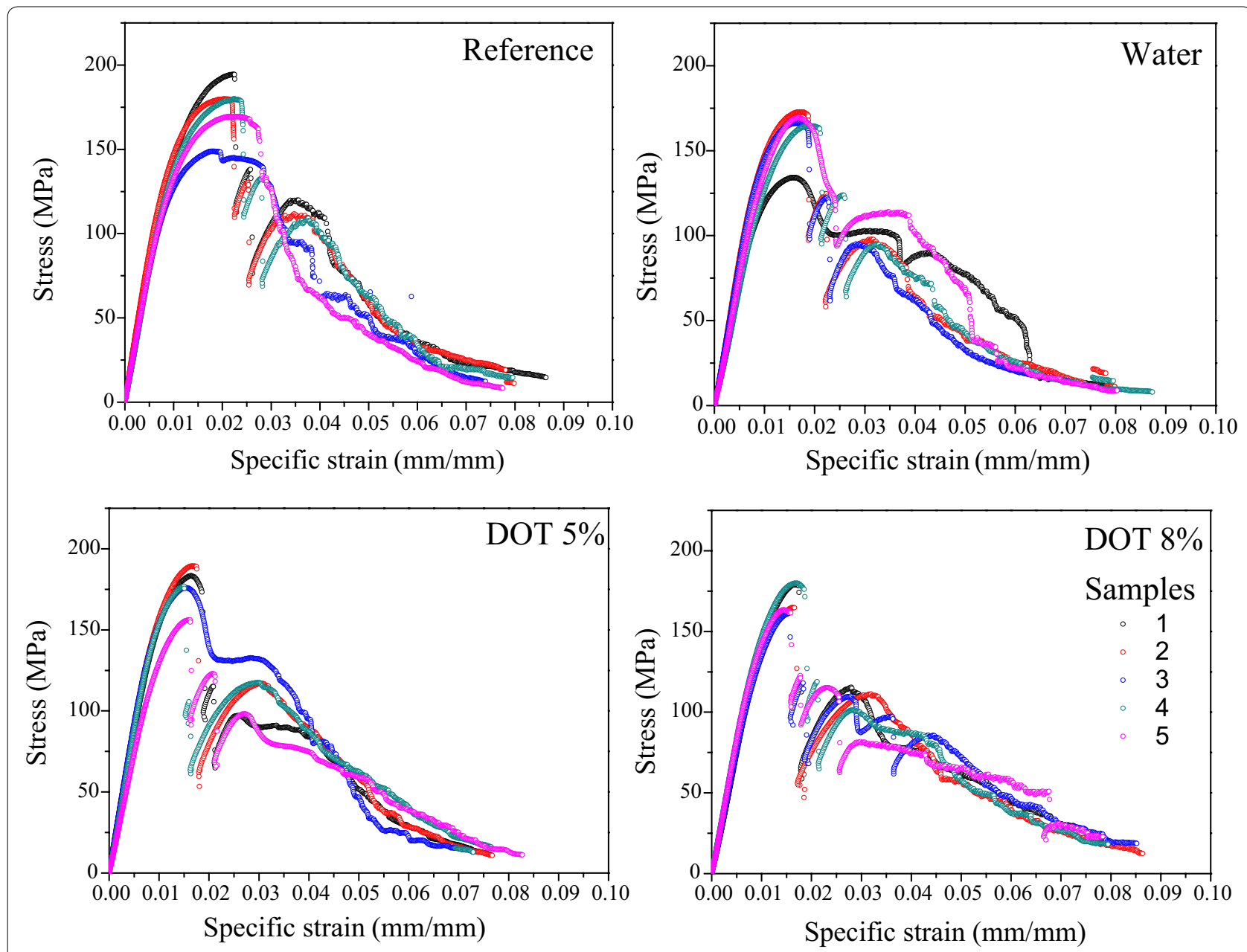

Fig. 5 Stress vs specific strain curves obtained by static bending of samples treated with DOT, water, and untreated

detrimental effect on the structure of bamboo even with high retention levels. Furthermore, it is possible to infer that the increase in the compressive strength can be correlated with the formed DOT salt crystals within the bamboo microstructure, which could help to accommodate the applied forces during loading. Since the $\mathrm{pH}$ of $5 \%$ and $8 \%$ solutions is close to neutral $\mathrm{pH}$ (between 7.9 and 7.7), which is one of the advantages over the use of only boric acid and borax as sources of boron, chemical reactions are not expected during treatment. In fact, preservatives with $\mathrm{pH}$ above 4.1 are not expected to cause considerable detrimental effects on wood properties [61]. Therefore, the increase in the mechanical properties found in this study is hypothesized to be attributed partially by the accommodations of forces by DOT crystals inside the bamboo porous structure or other mechanisms not yet known.

\section{Conclusions}

The effectiveness of an available commercial preservative-DOT-treatment on the mechanical properties of $D$. asper bamboo was investigated. In general, it was possible to conclude that there is no negative effect of DOT treatment on the investigated mechanical tests, even considering high DOT retention levels. The main conclusions are as follows:

- D. asper bamboo strips can be successfully vacuum/ pressure treated using boron compounds, achieving acceptable retention and penetration of DOT using $5 \%$ and $8 \%(\mathrm{wt} / \mathrm{wt} \%)$ solutions.

- For the dynamic MOE determined from the excitation pulse tests, there was no statistically significant change among the investigated conditions. 
Table 5 Summary of obtained results from three-point bending test

\begin{tabular}{|c|c|c|c|}
\hline Treatment conditions & MC (\%) & $\begin{array}{l}\text { MOR } \\
\text { (MPa) }\end{array}$ & $\begin{array}{l}\text { MOE } \\
(\mathrm{GPa})\end{array}$ \\
\hline \multicolumn{4}{|l|}{ Reference } \\
\hline Int A & 10.92 & $125.8(0.072)$ & $16.16(0.010)$ \\
\hline Int B & & $174.5(0.097)$ & $16.20(0.065)$ \\
\hline Overall Avr & & $156.2(0.18)$ & $16.18(0.050)$ \\
\hline Specific $^{1}$ & & $209.4(0.12)^{\mathrm{a}}$ & $21.97(0.10)^{\mathrm{a}}$ \\
\hline \multicolumn{4}{|l|}{ Water } \\
\hline Int A & 10.00 & $132.1(0.10)$ & $16.80(0.073)$ \\
\hline Int B & & $161.4(0.097)$ & $15.13(0.097)$ \\
\hline Overall Avr & & $150.4(0.14)$ & $15.76(0.098)$ \\
\hline Specific $^{1}$ & & $209.9(0.068)^{a}$ & $23.24(0.14)^{\mathrm{a}}$ \\
\hline \multicolumn{4}{|l|}{$5 \%$ DOT } \\
\hline $\operatorname{lnt} A$ & 10.70 & $134.8(0.087)$ & $15.69(0.055)$ \\
\hline Int B & & $176.4(0.071)$ & $17.12(0.089)$ \\
\hline Overall Avr & & $158.6(0.15)$ & $16.65(0.086)$ \\
\hline Specific $^{1}$ & & $227.3(0.091)^{\mathrm{a}}$ & $23.70(0.089)^{\mathrm{a}}$ \\
\hline \multicolumn{4}{|l|}{ 8\% DOT } \\
\hline $\operatorname{lnt} \mathrm{A}$ & 10.77 & $163.1(0.22)$ & $16.47(0.074)$ \\
\hline Int B & & $169.7(0.053)$ & $15.57(0.058)$ \\
\hline Overall Avr & & $167.2(0.13)$ & $15.91(0.066)$ \\
\hline Specific $^{1}$ & & $230.6(0.10)^{a}$ & $22.03(0.087)^{\mathrm{a}}$ \\
\hline
\end{tabular}

${ }^{1} \mathrm{MOE}(\mathrm{GPa}) / \rho\left(\mathrm{g} \mathrm{cm}^{-3}\right)$ and MOR (MPa) $/ \rho\left(\mathrm{g} \mathrm{cm}^{-3}\right)$. Specific averages with the same letter (a-d) are statically equivalent. Three replicates were tested for Int $A$ and five for Int B, with a total of eight replicates per treatment condition

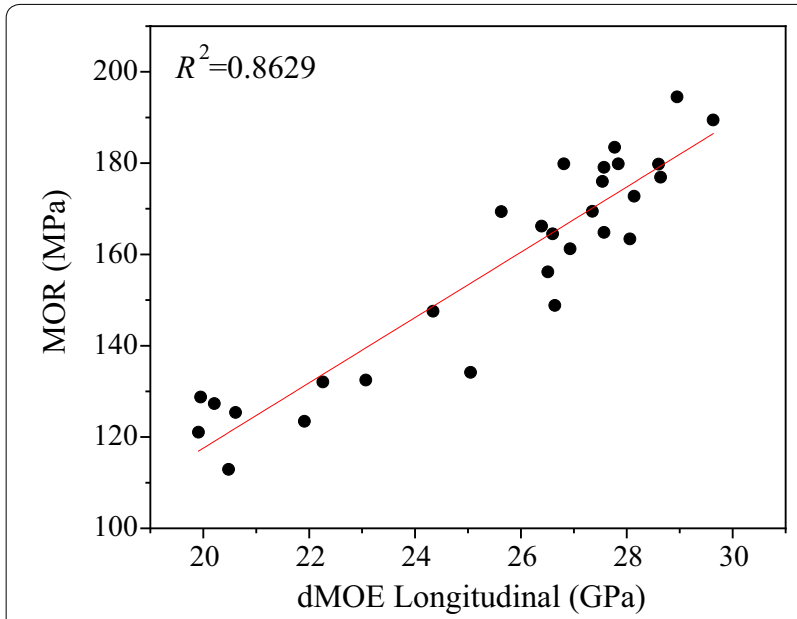

Fig. 6 Correlation between dynamic longitudinal MOE and the MOR obtained by static bending

- Although DOT treatment using both 5\% and 8\% concentration solutions positively affected specific MOR, the difference is not statistically valid.

- There is a linear correlation between dynamic MOE (NDT) and MOR obtained by static bending.
Table 6 Summary obtained results from compression tests parallel to fiber

\begin{tabular}{|c|c|c|c|}
\hline Treatment conditions & MC (\%) & $\begin{array}{l}C_{\mathrm{s}} \\
(\mathrm{MPa})\end{array}$ & $\begin{array}{l}E_{\mathrm{C}} \\
(\mathrm{GPa})\end{array}$ \\
\hline \multicolumn{4}{|l|}{ Reference } \\
\hline Int A & 9.74 & $50.3(0.064)$ & $17.64(0.032)$ \\
\hline Int B & & $65.4(0.050)$ & $32.00(0.12)$ \\
\hline Overall Avr & & $59.9(0.14)$ & $27.21(0.29)$ \\
\hline Specific $^{1}$ & & $81.8(0.073)^{\mathrm{a}}$ & $36.21(0.22)^{\mathrm{a}}$ \\
\hline \multicolumn{4}{|l|}{ Water } \\
\hline $\operatorname{lnt} \mathrm{A}$ & 9.10 & $60.3(0.056)$ & $18.04(0.13)$ \\
\hline Int B & & $74.3(0.067)$ & $25.49(0.14)$ \\
\hline Overall Avr & & $67.3(0.12)$ & $22.30(0.22)$ \\
\hline Specific $^{1}$ & & $95.80(0.081)^{b}$ & $32.10(0.17)^{\mathrm{a}}$ \\
\hline \multicolumn{4}{|l|}{$5 \%$ DOT } \\
\hline Int A & 9.61 & $68.0(0.059)$ & $17.07(0.18)$ \\
\hline Int B & & $82.5(0.042)$ & $29.65(0.10)$ \\
\hline Overall Avr & & $75.8(0.11)$ & $23.73(0.31)$ \\
\hline Specific $^{1}$ & & $110.7(0.056)^{c}$ & $34.59(0.20)^{\mathrm{a}}$ \\
\hline \multicolumn{4}{|l|}{$8 \%$ DOT } \\
\hline Int A & 8.95 & $73.4(0.11)$ & $20.35(0.13)$ \\
\hline Int B & & $78.0(0.045)$ & $30.57(0.14)$ \\
\hline Overall Avr & & $75.7(0.086)$ & $26.19(0.25)$ \\
\hline Specific $^{1}$ & & $106.8(0.056)^{c}$ & $36.84(0.18)^{\mathrm{a}}$ \\
\hline
\end{tabular}

$E_{c}:$ Compressive modulus of elasticity; $C_{\mathrm{s}}$ : compressive strength ${ }^{1} E_{\mathrm{c}}(\mathrm{GPa}) / \rho$ $\left(\mathrm{g} \mathrm{cm}^{-3}\right)$ and $C_{\mathrm{S}}(\mathrm{MPa}) / \rho\left(\mathrm{g} \mathrm{cm}^{-3}\right)$. Specific averages with the same letter $(\mathrm{a}-\mathrm{d})$ are statically equivalent. Six replicates were tested for Int $A$ and eight for Int $B$, with a total of 14 replicates per treatment condition

- Bamboo treated with 5\% and 8\% DOT solutions increased the compressive strength by $35.3 \%$ and $30.6 \%$, respectively, but no significant difference was observed in the modulus of elasticity in compression.

Additional degradation tests with decay fungi (white rot and brown rot) are currently being performed for the achievement of information regarding the effectiveness of DOT on the protection of bamboo against fungi before and after severe leaching cycles.

\section{Abbreviations}

DOT: disodium octaborate tetrahydrate; Int: internode; MC: moisture content; MOE: modulus of elasticity; MOR: modulus of rupture; NDT: nondestructive testing; $E_{c}$ : compressive modulus of elasticity; $C_{\mathrm{s}}$ : compressive strength; $\rho$ : apparent density.

\section{Acknowledgements}

CG thanks the financial support from São Paulo Research Foundation (FAPESP Grant 2016/26022-9) and MK thanks Coordination for the Improvement of Higher Education Personnel (CAPES Finance Code 001) for the development of this work. Authors are grateful to the Faculty of Animal Science and Food Engineering (FZEA/USP) administrative campus staff for helping in the bamboo harvesting process. The Research Nucleus on Materials for Biosystems 
(NAP BioSMat), USP Lab, is also deeply acknowledged for the infrastructure availability.

\section{Authors' contributions}

CG made the experimental work, including the treatments and mechanical/ physical characterization. CG also analyzed and interpreted the obtained data and was involved in organizing and writing the results presented in this manuscript. MK helped in the interpretation of the results and was an important contributor in writing the manuscript. HSJ was involved in drafting and revising the contents of this work. All authors read and approved the final manuscript.

\section{Funding}

The development of this work was funded by São Paulo Research Fundation (FAPESP Grant No. 2016/26022-9), Coordination for the Improvement of Higher Education Personnel (CAPES Finance Code 001) and National Council for Scientific and Technological Development (CNPq process 307723/2017-8).

\section{Availability of data and materials}

The datasets used and/or analyzed during the current study are available from the corresponding author on reasonable request.

\section{Competing interests}

The authors declare that they have no competing interests.

Received: 17 December 2018 Accepted: 14 June 2019

Published online: 22 June 2019

\section{References}

1. Huang L, Krigsvoll G, Johansen F, Lia L, Zhang X (2018) Carbon emission of global construction sector. Renew Sustain Energy Rev 81:1906-1916. https://doi.org/10.1016/j.rser.2017.06.001

2. Yan J, Zhao T, Lin T, LiY (2017) Investigating multi-regional cross-industrial linkage based on sustainability assessment and sensitivity analysis: a case of construction industry in China. J Clean Prod 142:2911-2924. https:// doi.org/10.1016/j.jclepro.2016.10.179

3. Chau CK, Hui WK, Ng WY, Powell G (2012) Assessment of $\mathrm{CO}_{2}$ emissions reduction in high-rise concrete office buildings using different material use options. Resour Conserv Recycl 61:22-34. https://doi.org/10.1016/j. resconrec.2012.01.001

4. Yuen JQ, Fung T, Ziegler AD (2017) Carbon stocks in bamboo ecosystems worldwide: estimates and uncertainties. For Ecol Manage 393:113-138. https://doi.org/10.1016/j.foreco.2017.01.017

5. Vogtländer JG, Van Der Velden NM, Van Der Lugt P (2014) Carbon sequestration in LCA, a proposal for a new approach based on the global carbon cycle; cases on wood and on bamboo. Int J Life Cycle Assess 19:13-23. https://doi.org/10.1007/s11367-013-0629-6

6. Escamilla EZ, Habert G (2014) Environmental impacts of bamboo-based construction materials representing global production diversity. J Clean Prod 69:117-127. https://doi.org/10.1016/j.jclepro.2014.01.067

7. Escamilla EZ, Habert G, Correal Daza J, Archilla HF, Echeverry Fernández JS, Trujillo D (2018) Industrial or traditional bamboo construction? Comparative life cycle assessment (LCA) of bamboo-based buildings. Sustainability 10:3096. https://doi.org/10.3390/su10093096

8. Chang FC, Chen KS, Yang PY, Ko CH (2018) Environmental benefit of utilizing bamboo material based on life cycle assessment. J Clean Prod 204:60-69. https://doi.org/10.1016/j.jclepro.2018.08.248

9. Vogtländer J, Van Der Lugt P, Brezet H (2010) The sustainability of bamboo products for local and Western European applications. LCAs and land-use. J Clean Prod 18:1260-1269. https://doi.org/10.1016/j.jclepro.2010.04.015

10. Yu D, Tan H, Ruan Y (2011) A future bamboo-structure residential building prototype in China: life cycle assessment of energy use and carbon emission. Energy Build 43:2638-2646. https://doi.org/10.1016/j.enbui ld.2011.06.013

11. Correal JF (2016) Bamboo design and construction. In: Harries KA, Sharma B (eds) Nonconventional and vernacular construction materials. Elsevier, Amsterdam, pp 393-431
12. Guo J, Tang J, Wen Y, Zhang JL, Li YS (2013) Development status of modern bamboo structure building. Appl Mech Mater 351-352:26-29. https //doi.org/10.4028/www.scientific.net/AMM.351-352.26

13. Sharma B, Gatóo A, Bock M, Ramage M (2015) Engineered bamboo for structural applications. Constr Build Mater 81:66-73. https://doi. org/10.1016/j.conbuildmat.2015.01.077

14. Archila H, Kaminski S, Trujillo D, Escamilla EZ, Harries KA (2018) Bamboo reinforced concrete: a critical review. Mater Struct 51:1-18. https://doi. org/10.1617/s11527-018-1228-6

15. Ghavami K, Marinho AB (2005) Physical and mechanical properties of the whole culm of bamboo of the Guadua angustifolia species. Rev Bras Eng Agrícola e Ambient 9:107-114. https://doi.org/10.1016/00137944(78)90069-3 (In Portuguese)

16. Chaowana P, Barbu MC (2017) Bamboo: potential material for biocomposites. In: Jawaid M, Md Tahir P, Saba N (eds) Lignocellulosic fibre and biomass-based composite materials: processing, properties and applications. Elsevier, Amsterdam, pp 259-289

17. Krause JQ, de Andrade Silva F, Ghavami K, Martins Gomes OF, Toledo Filho RD (2016) On the influence of Dendrocalamus giganteus bamboo microstructure on its mechanical behavior. Constr Build Mater 127:199-209. https://doi.org/10.1016/j.conbuildmat.2016.09.104

18. Srivaro S, Jakranod W (2016) Comparison of physical and mechanical properties of Dendrocalamus asper Backer specimens with and without nodes. Eur J Wood Wood Prod 74:893-899. https://doi.org/10.1007/s0010 7-016-1048-8

19. Awalluddin D, Mohd Ariffin MA, Osman MH, Hussin MW, Ismail MA, Lee $H$, Shukor Lim NHA (2017) Mechanical properties of different bamboo species. MATEC Web Conf 138:1-10. https://doi.org/10.1051/matec conf/201713801024

20. Ounjaijom T, Manee-inta N, Punyacum W (2017) Mechanical properties of five species dried bamboo. SWU Eng J 12:8-14

21. Ghavami K (2005) Bamboo as reinforcement in structural concrete elements. Cem Concr Compos 27:637-649. https://doi.org/10.1016/j.cemco ncomp.2004.06.002

22. Geroto P.G. (2014) Anatomical and physical characterization by X-ray densitometry of culms of Dendrocalamus asper Backer, Dendrocalamus latiflorus Munro and Guadua angustifolia Kunth (In Portuguese). Dissertation. University of São Paulo, Brazil

23. Ghavami K (2008) Bamboo: low cost and energy saving construction materials. In: Xiao Y, Inoue M, Paudel SK (eds) Modern bamboo structures. CRC Press, Changsha, pp 5-21

24. Liese W, Tang TKH (2015) Preservation and drying of bamboo. In: Liese W, Köhl M (eds) Bamboo: the plant and its uses. Springer, Cham, pp 257-297

25. Janssen JJA (2000) Designing and building with bamboo. International Network for Bamboo and Rattan, Eindhoven

26. Jayanetti DL, Follett PR (2008) Bamboo in construction. In: Xiao Y, Inoue M, Paudel SK (eds) Modern bamboo structures. CRC Press, Changsha, pp 23-32

27. Watanabe $H$, Yanase $Y$, Fujii $Y$ (2015) Evaluation of larval growth process and bamboo consumption of the bamboo powder-post beetle Dinoderus minutus using X-ray computed tomography. J Wood Sci 61:171-177. https://doi.org/10.1007/s10086-014-1458-3

28. Tiburtino RF, Paes JB, Vidaurre GB, Beraldo AL, Arantes MDC (2015) Resistance of two treated bamboo species against xylophagous fungi. Rev Árvore 39:567-574. https://doi.org/10.1590/0100-67622015000300018 (In Portuguese)

29. Xu M, Cui Z, Chen Z, Xiang J (2018) The charring rate and charring depth of bamboo scrimber exposed to a standard fire. Fire Mater. https://doi. org/10.1002/fam.2629

30. Harries KA, Sharma B, Richard M (2012) Structural use of full culm bamboo: the path to standardization. Int J Archit Eng Constr 1:66-75. https:// doi.org/10.7492/IJAEC.2012.008

31. Sulaiman O, Hashim R, Wahab R, Ismail ZA, Samsi HW, Mohamed A (2006) Evaluation of shear strength of oil treated laminated bamboo. Bioresour Technol 97:2466-2469. https://doi.org/10.1016/j.biortech.2005.10.026

32. Li T, Cheng DL, Wålinder MEP, Zhou DG (2015) Wettability of oil heattreated bamboo and bonding strength of laminated bamboo board. Ind Crops Prod 69:15-20. https://doi.org/10.1016/j.indcrop.2015.02.008

33. Wahab R, Mohamad A, Samsi HW, Sulaiman O (2005) Effect of heat treatment using palm oil on properties and durability of Semantan bamboo. J Bamboo Ratt 4:211-220. https://doi.org/10.1163/156915905774310034 
34. Wahab R, Salam MA, Mohamed A, Samsi HW, Rahman S, Rasat MSM, Khalid I (2015) Evaluation on strength of chemically treated 2 and 4 yearold bamboo Bambusa vulgaris through pressurized treatment. Res J Pharm Biol Chem Sci 6:1282-1288

35. Bui QB, Grillet AC, Tran HD (2017) A bamboo treatment procedure: effects on the durability and mechanical performance. Sustain 9:1-11. https:// doi.org/10.3390/su9091444

36. Lee CH, Yang TH, Cheng YW, Lee CJ (2018) Effects of thermal modification on the surface and chemical properties of moso bamboo. Constr Build Mater 178:59-71. https://doi.org/10.1016/j.conbuildmat.2018.05.099

37. Nguyen CT, Wagenfuhr A, Phuong LX, Dai VH, Bremer M, Fischer S (2012) The effect of thermal modification on the properties of two Vietnamese bamboo species, Part I: effects on physical properties. BioResources 7:5355-5366

38. Caldeira $F(2010)$ Boron in wood preservation a review in its physicochemical aspects. Silva Lusit 18:179-196

39. Kim T, Tang H, Liese W (2011) Pressure treatment of bamboo culms of three Vietnamese species with boron and CCB preservatives. J Bamboo Rattan 10:63-76

40. Zhou Z, Yao X, Du C et al (2018) Effect of Hygroscopicity of fire retardant on hygroscopicity of fire retardant bamboo chips. Wood Res 63:373-382

41. Jit Kaur P (2018) Bamboo availability and utilization potential as a building material. For Res Eng Int J 2:240-242. https://doi.org/10.15406/freij .2018.02.00056

42. Donmez Cavdar A, Mengelozlu F, Karakus K (2015) Effect of boric acid and borax on mechanical, fire and thermal properties of wood flour filled high density polyethylene composites. Meas J Int Meas Confed 60:6-12. https://doi.org/10.1016/j.measurement.2014.09.078

43. Tondi G, Wieland S, Lemenager N, Petutschnigg A, Pizzi A, Thevenon $M$ (2012) Efficacy of tannin in fixing boron in wood: fungal and termite resistance. BioResources 7:1238-1252

44. Sulaeman A, Dungani R, Nurudin N, Hartati S, Karliati T, Aditiawati P, Hadiyane A, Suhaya Y, Sulistyono (2018) Review on quality enhancement of bamboo utilization: preservation, modification and applications. Asian J Plant Sci 17:1-18

45. Prinindya KNN, Ardiansyah L (2014) The effect of chemical substance and immersion time of Dendrocalamus asper as chemical preservation treatment. Int J Adv Mater Sci Eng 3:1-13. https://doi.org/10.12962/j2354 6026.y2014i1.580

46. BIS IS1902 (2006) Preservation of bamboo and cane for non-structural purposes. Bureau of Indian Standards, New Delhi

47. Liese W (2004) Preservation of a bamboo culm in relation to its structure. Simposio Internacional del Bambu y la Guadua, Pereira

48. AWPA E10 (2016) Laboratory method for evaluating the decay resistance of wood-based materials against pure basidiomycete cultures: soil/block test. American Wood Protection Association, Selma, AL

49. ABNT Standard NBR 6232 (2013) Penetration and retention of preservatives in pressure treated wood. Brazilian Association of Technical Standards, Rio de Janeiro

50. ASTM Standard E1876 (2015) Standard test method for dynamic young's modulus, shear modulus, and poisson's ratio by impulse excitation of vibration. American Society of Testing and Materials, West Conshohocken, PA

51. ASTM Standard D1037 (2012) Standard test methods for evaluating properties of Wood-Base fiber and particle panel materials. American Society of Testing and Materials, West Conshohocken, PA

52. ABNT Standard NBR 7190 (1997) Wood Structures Project. Brazilian Association of Technical Standards, Rio de Janeiro

53. ASTM Standard D4761 (2013) Standard test methods for mechanical properties of lumber and wood-base structural material. American Society of Testing and Materials, West Conshohocken, PA

54. Lee SH, Ashaari Z, Lum WC, Halip JA, Ang AF, Tan LP, Chin KL, Tahir PM (2018) Thermal treatment of wood using vegetable oils: a review. Constr Build Mater 181:408-419. https://doi.org/10.1016/..conbuildma t.2018.06.058

55. Morrell JJ (2018) Protection of wood-based materials. Handb Environ Degrad Mater. https://doi.org/10.1016/B978-0-323-52472-8.00017-4

56. BIS IS401 (2001) Code of practice for preservation of timber. Bureau of Indian Standards, New Delhi

57. Baysal E, Tomak ED, Topaloglu E, Pesman E (2016) Surface properties of bamboo and Scots pine impregnated with boron and copper-based wood preservatives after accelerated weathering. Maderas Cienc y Tecnol 18:253-264. https://doi.org/10.4067/s0718-221×2016005000023

58. Dixon PG, Ahvenainen P, Aijazi AN, Chen SH, Lin S, Augusciak PK, Borrega M, Svedström K, Gibson LJ (2015) Comparison of the structure and flexural properties of Moso, Guadua and Tre Gai bamboo. Constr Build Mater 90:11-17. https://doi.org/10.1016/j.conbuildmat.2015.04.042

59. Arruda LM, Del Menezzi CHS, Teixeira DE, De Araújo PC (2011) Lignocellulosic composites from Brazilian giant bamboo (Guadua magna): part 1: properties of resin bonded particleboards. Maderas Cienc y Tecnol 13:49-58. https://doi.org/10.4067/S0718-221X2011000300005

60. Chung MJ, Wang SY (2018) Mechanical properties of oriented bamboo scrimber boards made of Phyllostachys pubescens (moso bamboo) from Taiwan and China as a function of density. Holzforschung 72:151-158. https://doi.org/10.1515/hf-2017-0084

61. Lahtela V, Hämäläinen K, Kärki T (2013) The effects of preservatives on the properties of wood after modification (Review paper). Balt For 20:189-203

\section{Publisher's Note}

Springer Nature remains neutral with regard to jurisdictional claims in published maps and institutional affiliations.

\section{Submit your manuscript to a SpringerOpen ${ }^{\odot}$ journal and benefit from:}

- Convenient online submission

- Rigorous peer review

- Open access: articles freely available online

- High visibility within the field

- Retaining the copyright to your article

Submit your next manuscript at $\boldsymbol{\nabla}$ springeropen.com 